\title{
COMERCIALIZAÇÃO DE PRODUTOS PELOS AGRICULTORES FAMILIARES NA FEIRA LIVRE DE SERRINHA-BA: UM DIAGNÓSTICO DAS PRÁTICAS
}

\section{PRODUCT COMMERCIALIZATION BY FAMILY FARMERS IN THE STREET FAIR OF SERRINHA- BA: A DIAGNOSIS OF THEIR PRATICES}

Andrea de Oliveira Silva

Elizabete Rodrigues da Silva

As feiras livres são mercados periódicos que resultam das potencialidades de cada região e, independentemente dos produtos comercializados, contribuem para o desenvolvimento local por meio da rede de relações sociais, culturais e econômicas entre cidades, especialmente tratando-se de municípios de pequeno e médio porte. Considerada um dos canais de comercialização dos produtos dos agricultores familiares, a feira livre propicia aos agricultores familiares o escoamento adequado da sua produção, gera renda e dinamiza a economia local. A comercialização de produtos dos agricultores familiares na feira livre constitui um processo complexo, porque envolve aspectos estruturais, tais como a cadeia produtiva, o transporte, o acondicionamento, a venda direta do produto ao consumidor e as relações com o poder público local. Entretanto, evidencia-se a necessidade de práticas de comercialização mais eficazes, de modo que, além de garantir o efetivo escoamento dos produtos da agricultura familiar, promovam o fortalecimento dos agricultores familiares como agentes econômicos que participam continuamente da feira livre. Nesta perspectiva, o objetivo do estudo foi elaborar um diagnóstico das práticas de comercialização dos produtos oriundos dos agricultores familiares na feira livre de Serrinha-BA. Para tanto, foi realizada uma pesquisa de abordagem qualitativa, descritiva, do tipo estudo de caso e, para a coleta dos dados, aplicaram-se questionários aos feirantes além da observação simples. Os resultados obtidos revelaram o perfil dos feirantes agricultores familiares e suas práticas. Observou-se, além da inadequação do local para comercialização, ausência de local para armazenagem, variação ineficaz ou desarranjada na precificação dos produtos, dificuldades com o seu transporte e precariedade na infraestrutura e na organização.

Palavras-chave: Comercialização. Agricultor Familiar. Feira Livre.

Free street fairs are periodic markets that result from the potential of each region and, independently of the products traded, contribute to local development through a network of social, cultural and economic relations between cities, especially in small and medium-sized municipalities. Considered as one of the marketing channels for the products of family farmers, the fair offers family farmers adequate outflow, generates income and stimulates local economy. The marketing of products from family farmers at the fair is a complex process because it involves structural aspects such as production chain, transportation, packaging, direct sale of the product to the consumer and relations with the local public power. However, it is evident that there is a need for more efficient marketing practices, so that, besides guaranteeing the effective flow of products from family agriculture, they promote the strengthening of family farmers as economic agents who continuously participate in the fair. Thus, the objective of the study was to elaborate a diagnosis of the commercialization practices of the family farmers' production in the sreet fair of Serrinha-BA. In order to attain our objective, a qualitative and descriptive case-study was carried out. Data were collected by means of a questionnaire and through observation of the fair grounds. The results obtained revealed the profile of farmers and their practices. The results show the inadequacy of the place for commercialization, absence of storage space, variation in product

\footnotetext{
${ }^{1}$ Graduada em Administração pela Escola de Negócios do Estado da Bahia ENEB. Especialista em Gestão de Pessoas Faculdade Visconde de Cairu, Mestre em Desenvolvimento Regional e Meio Ambiente FAMAM, Professora do curso de Administração da FAMAM e no Centro de Integração Empresa Escola - CIEE. Lattes https://wwws.cnpq.br/cvlattesweb/PKG_MENU.menu? f_cod=22533FE768F32F52B765E38D448AAB8Email: andreaosilva@yahoo.com.br

${ }^{2}$ Graduada em História pela Universidade do Estado da Bahia-UNEB, Mestre em História pela Universidade Federal da Bahia-UFBA e

Doutora em Estudos Interdisciplinares sobre Mulheres, Gênero e Feminismo pela Universidade Federal da Bahia-UFBA/NEIM. Professora e

Coordenadora do Mestrado Profissional em Desenvolvimento Regional e Meio Ambiente da Faculdade Maria Milza - FAMAM. Lattes -

http://buscatextual.cnpq.br/buscatextual/visualizacv.do?id=K4556749Z4 E mail betysilvk@yahoo.com.br
} 
pricing, difficulties with the transport of products, besides the precariousness of the infrastructure and organization.

Keywords: Marketing. Family Farmer. Street Fair.

\section{INTRODUÇÃO}

A agricultura familiar, no Brasil, desempenha um papel multifuncional em vários aspectos: na economia, na geração de renda, na função social de melhoria da qualidade de vida da população, bem como na conservação de recursos naturais e no cultivo de produtos.

De acordo com o Censo Agrário $2006^{3}$, houve um crescimento considerável de áreas plantadas pelos agricultores familiares no Brasil, e a produção passou de 70.303.362 toneladas em 1995/96 para 116.263.019 toneladas em 2006, referente aos produtos como arroz, feijão, mandioca, milho, soja, trigo e café. Além disso, a agricultura familiar foi a principal geradora de postos de trabalho no país, em 1996 com 13.780.201 e, em 2006 com 13.048.855, conforme dados do Instituto Nacional de Colonização e ReformaAgrária FAO/INCRA.

Por isso, a produção de produtos da agricultura familiar é considerada uma atividade econômica relevante em inúmeras regiões do Brasil. Entretanto, a representatividade da agricultura familiar na economia brasileira não condiz com a dinâmica de comercialização dos produtos pelos agricultores familiares. Entende-se que a comercialização de produtos pelos agricultores familiares é um processo complexo dentro do sistema da agricultura, que perpassa pelo entendimento da dinâmica que envolve a cadeia produtiva, desde a produção, a venda do produto agrícola até chegar ao consumidor final. As práticas de comercialização promovem diversas interações entre os agentes econômicos ${ }^{4}$ e não consistem apenas na venda do produto, mas caracterizam-se pela participação contínua do canal de comercialização.

O canal de comercialização é o caminho percorrido com o intuito de conduzir o produto ao consumidor final, sendo a feira livre considerada um desses canais utilizados pelos agricultores familiares. Essa atividade econômica é capaz de dinamizar a economia local, gerar empregos e renda, por meio da atuação de feirantes agricultores e feirantes comerciantes: no primeiro caso, produzem e comercializam os produtos, e no segundo, apenas revendem as mercadorias. Neste contexto, torna-se necessário compreender como se dão as práticas de comercialização desses produtos, as dificuldades enfrentadas pelos agricultores familiares e quais são os canais de comercialização que contribuem para o escoamento dos seus produtos, especificamente no contexto da feira livre.

As feiras livres são mercados periódicos que resultam das potencialidades locais, de feirantes, ambulantes e camelôs que lutam para sobreviver diante de um mercado formal, tecnologicamente evoluído. Trata-se de práticas que exercem um papel relevante na sociedade, contribuindo para o desenvolvimento local por meio de rede de relações sociais, culturais e econômicas entre cidades, especialmente em se tratando de municípios de pequeno e médio porte. Segundo Côrrea (1997), as feiras são mercados recorrentes, em ambientes pequenos que, povoados de forma periódica, se transformam em espaços com movimento intenso. Em um ambiente público de uma determinada localidade, reúnem-se comerciantes para comercialização de produtos oriundos de uma parte da população que desenvolve atividades primárias.

A dinâmica e a diversidade produtiva dos agricultores familiares ficam em evidência nas feiras livres. Para além da autossuficiência alimentar, envolvem também as formas de comercialização dos seus produtos. Em virtude da diversificação dos produtos da agricultura familiar, inúmeros agricultores familiares buscam formas para escoar sua produção.

\footnotetext{
${ }^{3} \mathrm{O}$ Censo agropecuário é uma pesquisa realizada pelo Instituto Brasileiro de Geografia e Estatística - IBGE a cada dez anos, no qual se reúnem informações sobre toda a atividade agrícola brasileira

${ }^{4}$ Agente(s) econômico(s): pode ser um indivíduo, conjunto de indivíduos, instituição ou conjunto de instituições que, por meio das suas decisões e ações, tomadas de forma racional, influenciam de alguma forma a economia, por exemplo, produtores, consumidores, instituições financeiras, instituições sociais (governo) ou ainda agentes que representam fenômenos do ambiente (regiões geográficas, clima) (TESFATSION, 2005).
} 
Nesse sentido, a presente pesquisa tem como objetivo geral elaborar um diagnóstico das práticas de comercialização dos produtos oriundos dos agricultores familiares no contexto da feira livre de Serrinha-BA. Para alcançá-lo, foi necessário conhecer o cenário da gestão e empreender os seguintes objetivos específicos: caracterizar o perfil dos feirantes agricultores familiares no contexto socioeconômico local; descrever as práticas de comercialização dos produtos dos agricultores familiares; identificar as forças, fraquezas, oportunidades e ameaças existentes na feira livre de Serrinha-BA.

\section{METODOLOGIA}

Trata-se de um estudo de caso descritivo quanto aos objetivos e de abordagem qualitativa, que responde a questões particulares sobre as práticas de comercialização de Feirantes Agricultores Familiares (FAFs) da feira livre de Serrinha-BA. Aárea estudada é o espaço da feira livre onde é realizada a comercialização de verduras, frutas, legumes e cereais, e que fica localizada na Rua 30 de Junho, s/n. Mede aproximadamente 100 metros de frente por 90 de fundo, ocupando uma área de 900 metros quadrados.

Conforme o último censo demográfico realizado no município de Serrinha-BA pelo Instituto Brasileiro de Geografia e Estatística - IBGE (2010), a população do município de Serrinha é de 76.762 habitantes; deste total, 30.108 residem na zona rural. A área da unidade territorial do município de Serrinha é de 613,695 km², contemplada com relevantes eixos rodoviários: são 04 rodovias - 01 federal (BR 116 norte, Serrinha- Feira de Santana) e 03 estaduais (BA409 - Rodovia do Sisal; BA 233 - Serrinha - Nova Soure, e BA411 Serrinha -Barrocas).

Para a coleta dos dados, aplicaram-se questionários aos FAFs para obter informação sobre a forma de armazenagem dos produtos da agricultura familiar, precificação, transporte, infraestrutura da feira livre, dificuldades na comercialização dos produtos e sugestões de melhorias. Após a coleta dos dados, as informações dos questionários respondidos pelos participantes foram tabulados e analisados.

Por fim, foi construído um diagnóstico das práticas de comercialização da feira livre de Serrinha, utilizando-se o modelo de matriz SWOT como técnica de análise de dados. A matriz de Swot é uma técnica que pode ser utilizada para qualquer tipo de análise de cenário, e se divide em ambiente interno (Forças e Fraquezas) e externo (Oportunidades eAmeaças).

\section{RESULTADOS E DISCUSSÃO}

As feiras livres são consideradas fenômenos econômicos e sociais por se constituírem de relações comerciais, de compra e venda de diversos produtos, e por se caracterizarem como espaços de múltiplas relações sociais entre sujeitos. Nas feiras livres, existe uma relação de compra e venda, cujas regras dependem tanto do produto a ser comercializado, quanto dos interesses e das relações que tecem os indivíduos envolvidos.

Ao analisar os dados referentes ao perfil dos sujeitos a partir da amostra de 154 feirantes agricultores familiares que comercializam na feira livre de Serrinha-BA, observa-se a predominância das seguintes características: sexo feminino, idade acima de 30 anos, estado civil solteiro, ensino fundamental completo, renda predominante de 1 a 2 salários mínimos, comercialização de produtos na feira livre há mais de 10 anos e comercialização de produtos provenientes tanto da zona rural do município de Serrinha-BA quanto de outros municípios.

Além do perfil, buscou-se conhecer os elementos que envolvem a comercialização dos produtos pelos feirantes agricultores familiares no canal de comercialização da feira livre de Serrinha-BA, considerando os seguintes aspectos: os tipos de produtos comercializados, o transporte, a forma de precificação, a área de comercialização dos produtos, locais de armazenagem, os programas de governo que beneficiam os agricultores, o destino dos produtos não comercializados, os concorrentes, bem como as dificuldades vivenciadas pelos agricultores na comercialização dos seus produtos. A Tabela 1 apresenta a distribuição dos produtos comercializados na feira livre no muncípio de Serrinha. 
Tabela 1. Produtos comercializados por feirantes agricultores familiares na feira livre de Serrinha-BA.

\begin{tabular}{lcc}
\hline Produtos comercializados & $\mathbf{N}^{\circ}$ de feirantes & \% (154) \\
\hline Legumes & 130 & 84 \\
Frutas & 83 & 54 \\
Verduras & 71 & 46 \\
Cereais & 55 & 36 \\
Hortaliças & 24 & 15 \\
Outros & 04 & 2 \\
\hline
\end{tabular}

Fonte: Dados da pesquisa, 2015.

Os números da Tabela 1 ilustram a diversidade dos produtos comercializados na feira livre e dentre eles destacam-se os legumes, as frutas e as verduras. Nessa perspectiva, compreende-se a relevância do tratamento dos produtos durante todo o percurso da comercialização. De acordo com Oliveira e Fagundes (2005), é importante o cuidado com os produtos que estão sendo comercializados, desde a colheita até o consumo. Os autores mencionam inadequações no transporte, armazenagem, manuseio e carregamento e descarregamento dos produtos no mercado.

Quanto aos transportes utilizados para o deslocamento dos produtos até a feira livre de SerrinhaBA, $54,5 \%$ dos feirantes agricultores (154 sujeitos) utilizam o transporte privado ${ }^{5}$, o que representa um número expressivo dos participantes desta pesquisa. $\mathrm{O}$ transporte pode ser de propriedade do próprio feirante ou ele paga pelo transporte dos produtos, uma vez que não utiliza o transporte público. Os demais agricultores familiares $(22,7 \%)$ utilizam o transporte público.

Quanto ao armazenamento, percebeu-se a ausência de espaço adequado para estoque e para comercialização dos produtos. O local de armazenagem é o mesmo espaço físico onde os produtos são expostos para serem comercializados. Segundo Gomes (1996), para o produto ser inserido e comercializado no mercado é preciso manter a sua qualidade, sendo a armazenagem um fator preponderante.

Em se tratando do espaço utilizado para a exposição e comercialização de produtos na feira livre de Serrinha-BA, tem-se dois dados e duas situações distintas confirmadas pelos agricultores familiares, a saber: $58,4 \%$ dos feirantes declararam que são alocados em espaços a céu aberto, e 41,6\% afirmam comercializar seus produtos em um espaço com cobertura.

Os FAFs que comercializam em áreas cobertas expõem e armazenam seus produtos nas mesmas caixas que fazem o transporte dos produtos. Outro fator adverso em tais ambientes são as telhas de fibrocimento que funcionam como cobertura de uma parte da área da feira livre. Como o fibrocimento absorve calor, eleva a temperatura do ambiente, o que provoca a perda de produtos e o mal estar dos consumidores e feirantes. Já os agricultores que comercializam nas áreas sem cobertura expõem e armazenam seus produtos em caixas de papelão no chão, sacos de nylon, baldes, bacias e sacolas plásticas expostos ao sol.

$\mathrm{Na}$ comercialização eficiente, a precificação dos produtos deve ser planejada pelos FAFs, com o objetivo de gerar equilíbrio entre a sua oferta e a sua demanda. No entanto, nem sempre o ato de comercializar em determinados canais de distribuição é garantia de lucratividade para os feirantes. $\mathrm{Na}$ feira livre de Serrinha, especificamente, devido às condições desfavoráveis em que os produtos estão acondicionados e aos problemas de transporte ou de produção, podem ocorrer variações de preço.

Em relação aos critérios de fixação de preço dos produtos comercializados na feira livre, $74,6 \%$ dos participantes afirmaram que fixam o preço com base no concorrente ${ }^{6}$, e 18,3\% afirmaram não saber como precificar o produto (Tabela 2). Os números obtidos na pesquisa sugerem que a maioria dos feirantes não realiza planejamento para fixar o preço, devido à falta de informação ou devido à cultura local dos feirantes.

\footnotetext{
${ }^{5} \mathrm{O}$ transporte privado compreende a modalidade de deslocamento em que os passageiros podem ser ou não os proprietários do veículo no qual os produtos são transportados.

${ }^{6} \mathrm{O}$ termo concorrente se refere aos feirantes que comercializam na feira livre, os supermercados, pequenos mercados e outras feiras livres.
} 
Tabela 2. Forma de fixação de preços dos produtos comercializados pelos agricultores familiares na feira livre de Serrinha, BA.

\begin{tabular}{lcc}
\hline \multicolumn{1}{c}{ Fixação de preço dos produtos } & $\mathbf{N}^{\circ}$ de feirantes & $\%$ \\
\hline Não sabe & 41 & 18,3 \\
Tem como base o preço da concorrência & 97 & 74,6 \\
Outros & 16 & 7,1 \\
\hline Total & 154 & 100 \\
\hline
\end{tabular}

Fonte: Dados da pesquisa, 2015.

Ainda em relação à variação dos preços dos produtos, é preciso considerar a sazonalidade; os períodos de chuva ou estiagem; pagamento de terceiros para o transporte do produto e o custo com a mão-de-obra no carregamento ou descarregamento de produtos. Por outro lado, também é comum no período de chuva que ocorra a diminuição dos preços devido à maior oferta dos produtos.

Na feira livre de Serrinha-BA não existe parâmetro para definição dos preços dos produtos que são comercializados, nem tabelas com preços pré-fixados ou leis municipais que determinem a precificação dos produtos vendidos pelos agricultores familiares. Eles utilizam o preço da concorrência para fixar o preço dos seus produtos, o que pode ser vantajoso ou desvantajoso para o consumidor, já que os preços não são fixos. Por outro lado, no momento da venda, a flexibilidade com a clientela pode ocasionar a definição de preços inadequados e a consequente ausência de lucro para o agricultor familiar.

Tendo em vista a alta perecibilidade dos produtos comercializados no mercado popular, procurouse conhecer o destino dos produtos que os feirantes não conseguiram comercializar na feira livre de Serrinha. Na Tabela 3 apresentamos as informações coletadas.

Tabela 3. Destino dos produtos não comercializados pelos feirantes agricultores familiares na feira livre.

\begin{tabular}{lcc}
\hline $\begin{array}{l}\text { Destino dos produtos não } \\
\text { comercializados na feira livre }\end{array}$ & $\begin{array}{c}\text { Frequência } \\
\text { (No de feirantes) }\end{array}$ & \%(154) \\
\hline Lixo & 85 & 55,2 \\
Consumo próprio & 69 & 44,9 \\
Não sobra & 40 & 26,0 \\
Doação & 20 & 13,0 \\
\hline
\end{tabular}

Fonte: Dados da pesquisa, 2015

Sobre o destino dos produtos que não são comercializados no ambiente da feira livre de Serrinha$\mathrm{BA}$, o descarte no lixo é a escolha mais frequente para 85 entrevistados; $69 \mathrm{FAFs}$ consomem os produtos não vendidos; 40 participantes afirmaram que não há sobra e, por fim, 20 feirantes doam os produtos não comercializados.

O lixo da feira, portanto, é acumulado e fica exposto no próprio espaço de comercialização, nas proximidades dos boxes e barracas. Por outro lado, os resíduos também são acumulados em um espaço conhecido como a "casa de lixo", que fica do lado de fora da feira livre e que é o local específico, onde uma empresa terceirizada da Prefeitura Municipal recolhe esses materiais em forma de entulho no final do dia.

Devido a que a maioria dos agricultores familiares joga os produtos não comercializados no lixo, esse acúmulo de grande quantidade de matéria orgânica nos faz refletir sobre o gerenciamento dos resíduos sólidos gerados na feira livre. Nesse sentido, o próprio gestor da feira livre afirma que a prestadora de serviços apenas realiza o recolhimento dos resíduos acumulados no final do dia, mas não faz o tratamento.

Tais contextos demandam regulamentos com orientações que contemplem aspectos sanitários e ambientais na feira livre, no sentido de contribuir com o processo de higienização dos espaços, onde se comercializam os produtos. Esses ambientes de comercialização, muitas vezes, não possuem coletores 
de lixo adequados, os resíduos dos produtos são jogados no chão, ocasionando mal cheiro, além de atraírem insetos e roedores, aspectos que prejudicam a comercialização e colocam em risco a saúde das pessoas envolvidas.

Existem muitas formas de gerenciamento do lixo; dentre elas destacam-se o aterro sanitário, a incineração, a compostagem e a reciclagem. Em se tratando dos tipos de resíduos gerados nas feiras livres, os dois últimos são considerados mais adequados.

A compostagem, é um processo antigo que permite a degradação dos resíduos orgânicos através de processos biológicos. O produto dessa degradação, a depender da qualidade, poderá servir de adubo para a agricultura ou a jardinagem. Para complementar este conceito, Coelho (2008, p. 5) mostra sua importância ao afirmar que "é um processo que pode ser utilizado para transformar diversos tipos de resíduos orgânicos em adubos que, quando acondicionados no solo, melhoram suas características físicas, físico-químicas e biológicas".

Já em relação ao processo de reciclagem do lixo, ocorre a partir da transformação dos resíduos da feira livre que podem ser reaproveitados. Esse processo requer uma coleta seletiva e a separação prévia dos materiais de acordo com os possíveis aproveitamentos.

Outro aspecto pesquisado foi o tipo de modalidade da comercialização dos produtos da agricultura familiar configurada como a modalidade de circuito curto. Caracteriza-se pela venda direta ao consumidor como a venda de produtos na própria propriedade, ou de forma indireta, com a presença de intermediadores para comercialização dos produtos junto aos consumidores. Mas, além da feira livre, os agricultores familiares comercializam seus produtos em outros locais, como no comércio local, na sua própria propriedade, em outras feiras livres, cooperativas, lojas especializadas, pequenos e grandes mercados, conforme a Tabela 4:

Tabela 4. Outros canais de comercialização de produtos dos feirantes - agricultores familiares.

\begin{tabular}{lcc}
\hline Outros locais de comercialização & $\begin{array}{c}\text { Frequência } \\
\text { No de agricultores }\end{array}$ & \% (154) \\
\hline Outras feiras livres & 75 & 49 \\
Pequenos mercados & 65 & 42 \\
Sua propriedade & 35 & 22 \\
Lojas especializadas & 03 & 2 \\
Grandes supermercados & 1 & 0,6 \\
Associações/ CoperativasPequenos mercados & 03 & 2 \\
\hline
\end{tabular}

Fonte: Dados da pesquisa, 2015.

Dentre os diversos locais de comercialização utilizados, as feiras livres são predominantes entre os agricultores familiares, realidade que corresponde a $49 \%$ deles. Em pequenos mercados a frequência foi de $42 \%$ e na própria propriedade foi de $22 \%$.

Os canais de distribuição utilizados pelos agricultores familiares são diversos, mas, de acordo com Ribeiro et al. (2005), a feira livre apresenta uma forma estratégica e viável de comercialização:

A solução local, por meio das feiras, são fundamentais nas estratégias familiares. Com dimensões variadas de tamanho, inserção e resultados, a feira semanal é um espaço dinâmico de comercialização, geração de renda e abastecimento. É também, sem dúvida, um espaço privilegiado para a criação de políticas públicas de apoio às famílias agricultoras (RIBEIRO et al., 2003, p. 3).

Nesse sentido, faz-se necessária a aplicação de estratégias na gestão da feira livre sobre as práticas de comercialização dos produtos dos agricultores familiares de Serrinha, com o intuito de fortalecer a comercialização dos produtos na feira livre, dando o apoio necessário aos agricultores 
familiares. Se existem diversos canais para os agricultores familiares escoarem seus produtos, entendese que a feira livre de Serrinha deverá estar preparada nos elementos básicos da gestão, a exemplo de estrutura adequada e organização que viabilize a venda dos produtos.

Consultando os feirantes agricultores familiares sobre as condições de trabalho na perspectiva de melhoria na comercialização de seus produtos, os mesmos expressaram sugestões que, possivelmente, irão melhorar o espaço, as relações de trabalho e a comercialização. A área de comercialização da feira livre de Serrinha apresenta potencial enquanto canal de comercialização, pois é extensa e de fácil acesso para os feirantes agricultores familiares e consumidores. Está localizada no centro da cidade de Serrinha, assim como tem proximidade com os povoados onde os feirantes residem. A feira livre é um ambiente que apresenta características culturais da região, a gratuidade do espaço, a variedade de produtos e possibilidade de escoamento dos mesmos.

Os FAFs apresentaram diversas sugestões para serem aplicadas à feira livre e, para torná-las mais compreensíveis, as agrupamos por meio das seguintes dimensões: gestão, social, ambiental e econômica.

$\mathrm{Na}$ dimensão gestão, os FAFs sugeriram cadastro dos feirantes; apresentação de normas padronizadas; criação de um canal de comunicação da gestão com os feirantes; capacitação dos funcionários que atuam na fiscalização e na limpeza; reuniões regulares entre gestores e feirantes; construção de boxes e barracas padronizados; ampliação do número de banheiros na feira; ampliação do espaço para inserção de mais agricultores familiares; construção de espaços para armazenagem de produtos; climatização do espaço da feira livre; melhoria da segurança; inserção de transporte público da zona rural para a zona urbana; reforma do espaço da feira para inserir coberturas e construção de barracas padronizadas.

No que se refere à dimensão social, foi sugerida a extinção das proteções político-partidárias e, na dimensão econômica, a cobrança pelo espaço, criação de cooperativas e fixação de preços dos produtos. Por fim, no que diz respeito à dimensão ambiental, os FAFs sugeriram a melhoria na higenização dos produtos a serem vendidos bem como da estrutura da feira livre e o gerenciamento dos resíduos que ela gera.

Diante das alternativas propostas, as principais ações que podem beneficiar a comercialização dos produtos na feira livre de Serrinha-BA são: ampliar o espaço na área coberta utilizada para atender a uma maior demanda de feirantes; construir espaços para armazenagem de produtos; organizar os horários de funcionamento; colocar cobertura nos espaços descobertos da feira livre; inserir transportes gratuitos para ajudar os menos favorecidos no transporte dos produtos; elaborar e disseminar o regimento interno em conjunto com os feirantes agricultores familiares.

A partir deste cenário, construiu-se a matriz SWOT como técnica de análise de dados para determinar, em ambiente interno, as Forças e Fraquezas e, no ambiente externo, as Oportunidades e Ameaças, permitindo elaborar o diagnóstico das práticas de comercialização da feira livre de Serrinha, conforme mostramos no quadro a seguir. 


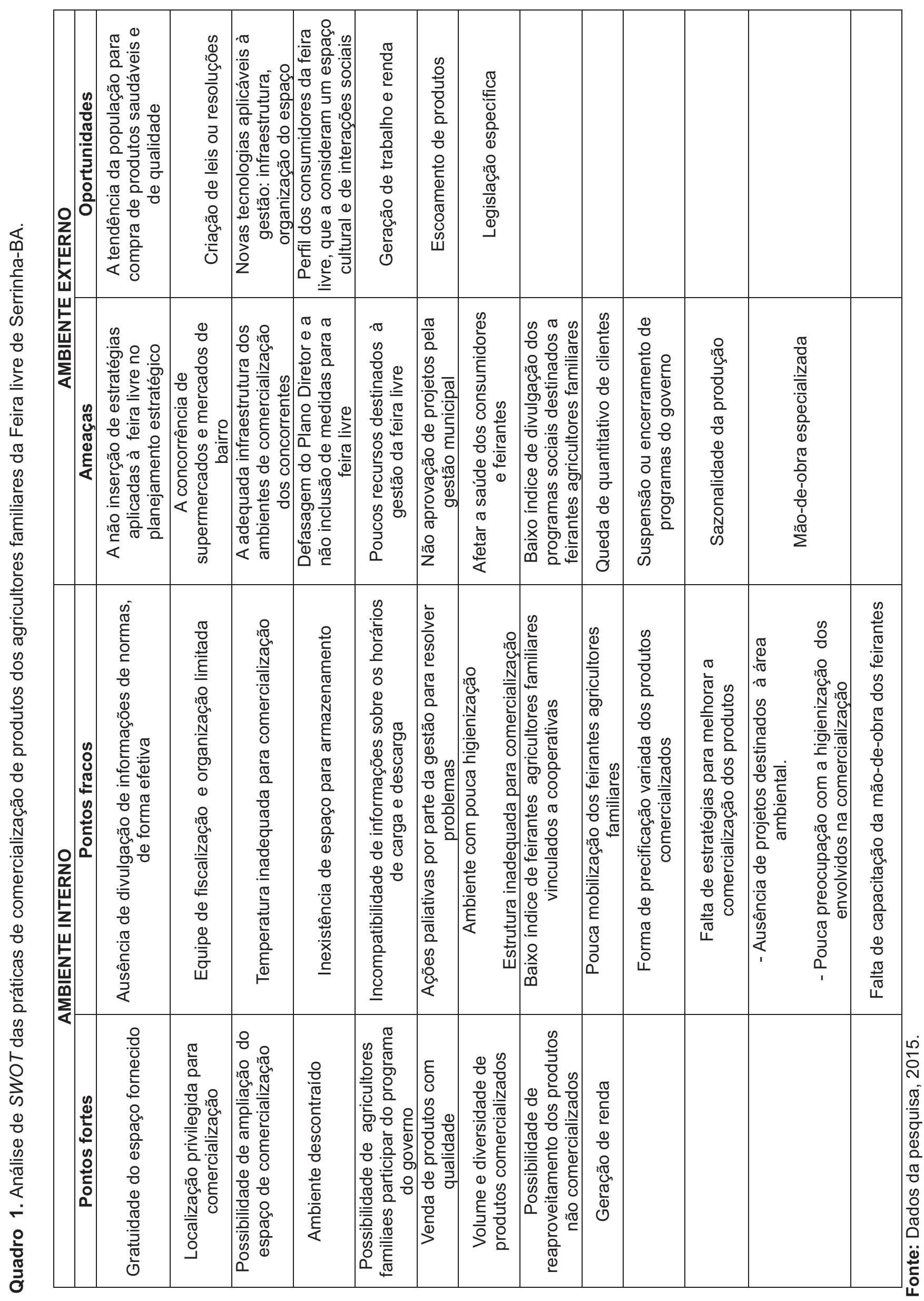




\section{CONSIDERAÇÕES FINAIS}

A feira livre pode ser considerada uma atividade econômica relevante, porque representa uma das formas mais antigas de comercialização que, até hoje, desenvolve um importante papel econômico, social e cultural ao aglutinar diversas atividades comerciais exercidas por pessoas oriundas tanto da zona rural quanto urbana, para permitir a circulação de riqueza de produtos e do patrimônio cultural produzido localmente.

Este artigo teve como propósito apresentar elementos que envolvem a comercialização de produtos na feira livre, considerado um espaço público de interações sociais, culturais e políticas. No diagnóstico das práticas de comercialização, por meio da análise SWOT, foram percebidos fatores relevantes desenvolvidos na feira, tais como: a gratuidade do espaço; localização privilegiada para comercialização dos produtos; possibilidade de ampliação do espaço para comercialização; um ambiente desconstraído para trabalhar; possibilidade de comercialização de produtos de qualidade; geração de renda; diversidade de produtos comercializados; possibilidades de reaproveitamento de produtos não comercializados.

Entretanto, identificaram-se problemas que perpassam pela fragilidade na gestão do espaço público, tais como: ausência de informações e divulgações de normas; desorganização do espaço; ambiente com temperatura inadequada para comercialização; inexistência de espaço para armazenamento dos produtos; estrutura inadequada; ambiente com pouca higienização; descompromisso dos envolvidos com a higienização do espaço. Essa análise perpassou a visão do agicultor perante a atuação do gestor, mas precisamos entender que os feirantes também possuem sua responsabilidade nas práticas básicas de comercialização.

A partir de tal realidade, sugere-se a participação dos feirantes agricultores familiares nos processos decisórios através de representantes da categoria. Compreende-se que a vivência dos sujeitos dessa pesquisa permite uma melhor concepção sobre os espaços das práticas de comercialização, mas ressaltamos que os agricultores precisam se conscientizar do seu papel, tais como: higienização dos produtos, limpeza e organização do espaço, respeito às normas e cuidado com todo o ambiente de comercialização.

Neste contexto, recomenda-se aos responsáveis pela gestão da feira livre a sua modernização; a capacitação dos funcionários para uma efetiva fiscalização; a elaboração de diretrizes organizacionais no intuito de sistematização e divulgação das normas aos envolvidos. Portanto, entendemos a necessidade da manutenção dos espaços da feira livre por meio de sua organização. Além disso, a gestão precisa fortalecer a imagem do feirante, considerando-o como empreendedor, melhorarando o seu potencial enquanto comerciante e, por fim, tornar a feira livre um espaço cultural e gerador de renda.

Por fim, cabe ressaltar que uma dificuldade vivenciada nesta pesquisa foi a ausência de dados sobre o volume dos produtos comercializados, assim como os cadastros dos agriculturos na feira livre de Serrinha-BA. Sugere-se a gestão da feira livre a construção de planilhas eletrônicas de acompanhamento referente ao quantitativo mensal de vendas, com o intuito de mensurar o volume dos produtos comercializados, facilitando a produção de novas pesquisas.

\section{REFERÊNCIAS}

COELHO, F. C.. Composto Orgânico. Niterói: Programa Rio Rural, 2008. In:.DAYCHOUM. M. 40 + 4 ferramentas e técnicas de gerenciamento. Angelo Vale . 3 Ed. Rio de Janeiro: Brasport, 2010.

CÔRREA. R. L. Interações espaciais. In: CASTRO, I. E. de; GOMES, P. C. da C. In: CÔRREA, R. L. (Org.). Explorações Geográficas. Rio de Janeiro: Bertrand Brasil, 1997. p. 279-318.

IBGE. Censo agropecuário. Agricultura Familiar - Brasil, Grandes Regiões e Unidades da Federação. 2006.

Disponível em: Agrohttp://www.ibge.gov.br/home/estatistica/economia/agropecuaria/ censoagro/agri_familiar_2006.Acesso em: 16 jan. 2016. 
IBGE: Instituto Brasileiro de Geografia e Estatística. Características da População e dos Domicílios: Resultados d o Un iverso. D is ponível e m: $<$ h t p: //www.ibge.gov.br/home/estatistica/populacao/censo2010/caracteristicas_da_populacao/default_caracteristicas_ da_populacao.shtm>.Acesso em 10 de março. 2014

INCRA/FAO/MPFDA. Estudos de Sistemas Agrários nos Municípios de Boa Ventura, PR e Quilombo, SC. In: AGRICULTURAFAMILIAR EM ÁREAS DE REFORMAAGRÁRIA: Região Sul. Brasília, 2000.

GOMES, M. S. de O. Conservação pós-colheita: frutas e hortaliças. Brasília: Embrapa-SPI, 1996.

OLIVEIRA, A. L. R.; FAGUNDES, P. R. S. O papel da logística na cadeia de produção de hortifrutis. São Paulo: IEA, 2005. Disponível em: <http://www.iea.sp.gov.br/out/verTexto.php?codTexto=2160>. Acesso em: 05 nov. 2015.

RIBEIRO, E.M., GALIZONI, F.M., CALIXTO, J.S., ASSIS, T.R., AYRES, E.B., SILVESTRE, L.H. Gestão, uso e conservação de recursos naturais em comunidades rurais do alto Jequitinhonha. Revista Brasileira de Estudos Urbanos e Regionais. V. 7, N. 2, nov 2005. Disponível em: http://rbeur.anpur.org.br/rbeur/article/view/146 Acesso em: 05 nov. 2015.

RIBEIRO, E. M.; ÂNGULO, J.L.G; NORONHA, A. B; CASTRO, B.S; GALIZONI, F.M.;CALIXTO,J.S., SILVESTRE, L.H. A feira e o trabalho rural no Alto Jequitinhonha: um estudo de caso em Turmalina, Minas Gerais. UNIMONTES CIENTífICA. Montes CIaros, v.5, n.1, jan./jun. 2003 . Disponível em: http://www.ruc.unimontes.br/index.php/unicientifica/article/view/53. Acesso em: 05 nov. 2015.

TESFATSION, L. Economia Computacional Baseada em Agente: uma abordagem construtiva a teoria econômica . [ S. L. ] : Sociedade de Economia Computacional, 2005. 